\title{
Connexin subtype expression during oral carcinogenesis: A pilot study in patients with oral squamous cell carcinoma
}

\author{
PHILLIPP BROCKMEYER ${ }^{1}$, BERNHARD HEMMERLEIN ${ }^{2,3}$, KLAUS JUNG $^{4}$, \\ FLORIAN FIALKA $^{5}$, TOBIAS BRODMANN ${ }^{6}$, RUDOLF MATTHIAS GRUBER ${ }^{1}$, \\ HENNING SCHLIEPHAKE ${ }^{1}$ and FRANZ-JOSEF KRAMER ${ }^{1}$
}

\begin{abstract}
Departments of ${ }^{1}$ Oral and Maxillofacial Surgery and ${ }^{2}$ Pathology, University Medical Centre Goettingen, D-37075 Goettingen; ${ }^{3}$ Institute of Pathology, Krefeld Helios Hospital, D-47805 Krefeld; ${ }^{4}$ Department of Medical Statistics, University Medical Centre Goettingen, D-37075 Goettingen; ${ }^{5}$ Private Practice, MKG Leinetal, D-37574 Einbeck; ${ }^{6}$ Private Practice, Zahnarztpraxis am Westertor, D-37115 Duderstadt, Germany
\end{abstract}

Received August 5, 2015; Accepted November 10, 2015

DOI: $10.3892 / \mathrm{mco} .2015 .685$

\begin{abstract}
Gap junctional intercellular communication (GJIC) and connexin (Cx) expression were reported in association with carcinogenesis in various types of tumours. In an earlier histomorphometric study, the protein levels of Cx subtypes 26, 43 and 45 were differentially expressed in oral squamous cell carcinoma (OSCC), corresponding lymph node metastases and dysplasia-free oral mucosa. Moreover, membrane $\mathrm{Cx} 43$ acted as an independent prognostic marker in OSCC tissues. This study aimed to confirm the expression of described Cx subtypes at the mRNA level. Hence, a reverse transcription quantitative polymerase chain reaction (RT-qPCR) analysis of Cx 26, Cx43 and $\mathrm{Cx} 45$ gene expressions was performed in paired carcinoma and mucosa samples of 15 OSCC patients. Additionally, we assessed the interaction between $\mathrm{Cx}$ subtype expression and clinicopathological routine parameters. The RT-qPCR analysis revealed that $\mathrm{Cx} 26$ was downregulated in OSCC $(\mathrm{P}=0.01)$, while $\mathrm{Cx} 43$ was marginally upregulated in cancer tissue $(\mathrm{P}=0.04)$. $\mathrm{Cx} 45$ was significantly overexpressed in OSCC tissue compared with the intraoral mucosa controls $(\mathrm{P}<0.01)$, and remained unchanged at different tumour stages. No significant interactions between differential $\mathrm{Cx}$ subtype expression and clinicopathological routine parameters were observed. In conclusion, $\mathrm{Cx}$ regulation at the transcriptional level appears to be an early event during the initiation and development of OSCC, and is maintained during further progression. However, the mRNA-protein correlation is variable. This may be indicative of post-transcriptional, translational and degradation regulations being associated
\end{abstract}

Correspondence to: Dr Phillipp Brockmeyer, Department of Oral and Maxillofacial Surgery, University Medical Centre Goettingen, 40 Robert-Koch-Street, D-37075 Goettingen, Germany E-mail:ph.brockmeyer@gmail.com; ph.brockmeyer@orcid.org

Key words: oral squamous cell carcinoma, gap junctional intercellular communication, connexin 26, connexin 43, connexin 45 , connexin regulation with the determination of $\mathrm{Cx}$ protein concentration during oral carcinogenesis.

\section{Introduction}

Contiguous connexins (Cxs) may form homomeric or heteromeric gap junction hemichannels (connexons) on the cell membrane (1). Two connexons of adjacent cells form a gap junction channel, through which gap junction intercellular communication (GJIC) is possible via the passage of ions and second messengers (1). GJIC plays a crucial role in maintaining cell homeostasis, cell growth control and development (1).

First described in cultured hepatoma cells (2), the association between GJIC and carcinogenesis has since been described in various types of tumours, such as cervical $(3,4)$, mammary (5), bronchial (6) and colorectal carcinoma (7). Depending on tumour progression, GJIC has different functions (8). Cxs affect cell growth by affecting the expression of cell cycle regulatory genes, such as cyclin A, D1 and D2, and cyclin-dependent kinases (8). Cx43 transfection in previously deficient tumour cell lines led to growth inhibition and an accumulation of classical tumour suppressors, such as p27 and Rb protein (8). Lack of GJIC leads to an intracellular accumulation of growth factors (2) and suppressed contact inhibition, causing cell proliferation (9). King et al (4) described a correlation between endogenous Cx43 mRNA and protein expression and increased growth control, with decreased growth capacity in HeLa cervical cancer cells. Cx43 knockout in mice leads to astrocytes exhibiting altered expression of genes associated with apoptosis, cell growth, transcription factors $(10,11)$, and increased susceptibility of mice to pulmonary neoplasia (6). $\mathrm{Cx} 26$ and $\mathrm{Cx} 43$ expression in MDA-MB-231 breast cancer cells (5) provided similar results. $\mathrm{Cx} 26$ is responsible for contact growth inhibition in HeLa and HepG2 cells $(3,12)$. Cx45 may form heteromeric gap junctions along with $\mathrm{Cx} 43$, and may affect intercellular contacts during carcinogenesis (13-15). Cx subtypes increase the attachment of tumour cells to the stroma (8) and the endothelial barrier (16), thereby promoting invasion and metastatic spread. Cx26 was identified in melanoma cells and surrounding small vessel 
endothelia (17), as well as in squamous cell lung carcinoma and its associated lymph node metastases (LMNs) (18). Cx26- and Cx43-negative primary breast cancers developed Cx26- and Cx43-positive LMNs (19). Glioma cells establish functional gap junctions comprising $\mathrm{Cx} 43$ with astrocytes in the adult brain, thus facilitating direct parenchymal invasion (20).

For oral squamous cell carcinoma (OSCC), conflicting Cx expression data were reported by Ozawa et al (21) and Villaret et al (22), who described Cx26 and Cx30 expression in OSCC tissues. In a previous histomorphometric study, we analysed the protein expression of Cx subtypes 26, 43 and 45 in tissue samples of OSSC, corresponding LMNs and dysplasia-free oral mucosa in 35 patients (23). In addition to significantly different expression patterns between the studied tissue types, high membrane $\mathrm{Cx} 43$ expression in OSCC tissues was found to be associated with poor prognosis (23). Xia et al (24) previously reported reduced Cx43 protein concentration, despite normal mRNA levels, in an induced rat tongue carcinogenesis model. The present study aimed to confirm the expression of the described Cx subtypes at the mRNA level by conducting a reverse transcription quantitative polymerase chain reaction (RT-qPCR) analysis in 15 tissue sample pairs of OSCC and corresponding oral mucosa.

\section{Materials and methods}

Patients. Tissue samples from 15 patients suffering from primary OSCC were analysed. All the patients were diagnosed and treated according to the guidelines of the national German Oral Cancer Association (25). The resection margins and presence of LMNs were histologically investigated in all the patients. Metastases to the lung, liver and bone marrow were evaluated by chest radiography, abdominal ultrasound examination and bone scans in all the patients. The patients' characteristics are summarised in Table I. The patients provided written informed consent prior to participating in the study. This study was conducted in line with the ethical standards of the Declaration of Helsinki and was approved by the local Ethics Committee at the George-August-University of Goettingen (vote number 11/6/05).

Biopsies. One biopsy from OSCC tissue and one from tumour-free oral mucosa were obtained from each patient during tumour ablation. All the biopsies were 2-3 $\mathrm{mm}$ in diameter. Sampling was performed according to a predefined, standardized working instructions, based on size and location of sampling, by the same two experienced examiners (F.F. and R.M.G.). The biopsies were incubated in RNAlater ${ }^{\circledR}$ (Ambion/Applied Biosystems, Darmstadt, Germany) overnight and shock-frozen in liquid nitrogen for storage at $-80^{\circ} \mathrm{C}$ until RNA isolation.

RNA isolation. RNA was isolated using the RNeasy Mini kit (Qiagen, Hilden, Germany) according to the manufacturers' recommendations and stored at $-80^{\circ} \mathrm{C}$. Subsequently, the samples were treated with DNase I to remove genomic DNA contaminations. The RNA quality was determined using the Agilent 2100 Bioanalyzer (Agilent Technologies, Boeblingen, Germany) microfluidic electrophoresis. The analysed tissue sample pairs (OSCC and oral mucosa) had comparable RNA integrity numbers.

$R T-q P C R$. For verification of Cx subtype expression, RNA samples were converted into cDNA using the Bio-Rad iScript cDNA Synthesis kit (Bio-Rad Laboratories, Munich, Germany) and quantified on a Bio-Rad MyiQ Real-Time PCR Detection system with the Bio-Rad iQ SYBR Green Supermix. The primers are listed below:

GAPDH: 5'-GAGTCAACGGATTTGGTCGT-3', 5'-GAC AAGCTTCCCGTTCTCAG-3'; Cx26: 5'-ACTCCACCAGCA TTGGAAAG-3', 5'-TGGGAGATGGGGAAGTAGTG-3'; Cx43: 5'-AGCAGTCTGCCTTTCGTTGT-3', 5'-TCTGCT TCAAGTGCATGTCC-3'; and Cx45: 5'-GCACTGCCAGTA GCAAATCA-3', 5'-CCAACAGCATCCCTGAAGAT-3'.

Relative gene expression was quantified using the $\Delta \Delta \mathrm{Cq}$ method. Since GAPDH is not differentially expressed in OSCC tissue (26), it was used as a housekeeping gene, based on which the $\mathrm{Cx}$ gene expression was normalized.

Statistical analysis. Relative gene expression normalized to GAPDH and $\log _{2}$-transformed was calculated from $\mathrm{Cq}$ values and PCR efficiency (27). The expression change between OSCC and oral mucosa and the effect of clinicopathological routine parameters was separately assessed for Cx26, Cx43 and Cx45 by a multivariate linear regression model. To account for the matched-pair situation (i.e., OSCC and normal mucosa from the same patient), patients were included as random-effects term to each model. For tissue and other dichotomous model parameters, the regression coefficients may be considered as $\log _{2}$ fold changes and are reported with their related standard errors. The significance level was set to $\alpha=5 \%$ for each test. For a stronger statistical perspective, the P-values for the tissue effects were adjusted by the method of Bonferroni and Holm (28). All the analyses were performed using $\mathrm{R}$ software, version 3.1 (www.r-project.org). The multivariate regression models were fitted with the lmer function of the lme4 package for R.

\section{Results}

Differential CX expression in OSCC and normal oral mucosa. The multivariate model analysis yielded a significant differential expression between the two types of tissues (OSCC and oral mucosa) for each of the three $\mathrm{Cx}$ subtypes. In detail, $\mathrm{Cx} 45$ exhibited a strong overexpression of 10.5-log-fold (95\% CI: 7.6-13.4) in OSCC samples and was differentially expressed compared with tumour-free oral mucosa controls $(\mathrm{P}<0.01)$. Cx26 exhibited a downregulation of -8.4-log-fold (95\% CI: -14.1 to -2.7$)$ in cancer tissues $(\mathrm{P}=0.01)$. Compared with oral mucosa controls, the gene expression for $\mathrm{Cx} 43$ was marginally upregulated $(\mathrm{P}=0.04)$ in OSCC tissues (0.7-log-fold; 95\% CI: 0.1-1.3; Fig. 1). Following a Bonferroni/Holm-adjustment, the P-values for the tissue effects remained statistically significant. The gene expression of the described Cx subtypes did not differ between the early and late stages of malignancy, and there were no significant effects by the clinicopathological routine parameters $\mathrm{T}$ status, $\mathrm{N}$ status and American Joint Committee on Cancer stage. Moreover, Cx subtype expression was not found to be correlated with alcohol and tobacco abuse, gender, or histopathological grade. Only for $\mathrm{Cx} 43$, the P-value 
Table I. Descriptive statistics and results from multivariate regression models with expression levels as the dependent variable.

\begin{tabular}{|c|c|c|c|c|c|c|c|}
\hline \multirow[b]{2}{*}{ Parameters } & \multirow{2}{*}{$\begin{array}{c}\text { Descriptive } \\
\text { statistics }\end{array}$} & \multicolumn{2}{|c|}{$\mathrm{Cx} 26$} & \multicolumn{2}{|c|}{$\mathrm{Cx} 43$} & \multicolumn{2}{|c|}{$\mathrm{Cx} 45$} \\
\hline & & $\beta \pm \mathrm{SE}$ & P-value & $\beta \pm \mathrm{SE}$ & P-value & $\beta \pm \mathrm{SE}$ & P-value \\
\hline Tumour tissue & & $-8.4 \pm 2.9$ & 0.01 & $0.7 \pm 0.3$ & 0.04 & $10.5 \pm 1.5$ & $<0.01$ \\
\hline Age (years) & $59.0 \pm 12.9$ & $-0.1 \pm 0.2$ & 0.45 & $-0.02 \pm 0.02$ & 0.22 & $-0.1 \pm 0.1$ & 0.50 \\
\hline Gender & & $-3.7 \pm 6.3$ & 0.58 & $-0.6 \pm 0.6$ & 0.33 & $1.8 \pm 7.2$ & 0.81 \\
\hline Female & $5(33 \%)$ & & & & & & \\
\hline Male & $10(67 \%)$ & & & & & & \\
\hline T status & & $-10.8 \pm 26.2$ & 0.69 & $0.7 \pm 2.7$ & 0.80 & $-4.7 \pm 27.6$ & 0.87 \\
\hline Is & $1(7 \%)$ & & & & & & \\
\hline 2 & $5(33 \%)$ & & & & & & \\
\hline 4 & $8(53 \%)$ & & & & & & \\
\hline $4 a$ & $1(7 \%)$ & & & & & & \\
\hline $\mathrm{N}$ status & & $6.4 \pm 3.5$ & 0.12 & $0.5 \pm 0.4$ & 0.17 & $0.5 \pm 3.7$ & 0.90 \\
\hline 0 & $9(60 \%)$ & & & & & & \\
\hline 1 & $3(20 \%)$ & & & & & & \\
\hline $2 b$ & $2(13 \%)$ & & & & & & \\
\hline $2 \mathrm{c}$ & $1(7 \%)$ & & & & & & \\
\hline Nicotine abuse & & $-0.7 \pm 9.1$ & 0.94 & $0.01 \pm 0.9$ & 0.99 & $-14.3 \pm 8.0$ & 0.14 \\
\hline Yes & $14(93 \%)$ & & & & & & \\
\hline No & $1(7 \%)$ & & & & & & \\
\hline Alcohol abuse & & $6.9 \pm 3.5$ & 0.22 & $-1.0 \pm 0.5$ & 0.05 & $-4.2 \pm 4.3$ & 0.37 \\
\hline Yes & $10(67 \%)$ & & & & & & \\
\hline No & $5(33 \%)$ & & & & & & \\
\hline Stage & & $8.4 \pm 24.4$ & 0.74 & $-0.6 \pm 2.5$ & 0.82 & $1.3 \pm 25.4$ & 0.96 \\
\hline 0 & $1(7 \%)$ & & & & & & \\
\hline 2 & $5(33 \%)$ & & & & & & \\
\hline 4 & $9(60 \%)$ & & & & & & \\
\hline Grade & & $1.0 \pm 4.8$ & 0.84 & $-0.7 \pm 0.5$ & 0.18 & $4.4 \pm 4.2$ & 0.34 \\
\hline 1 & $2(13 \%)$ & & & & & & \\
\hline 2 & $11(74 \%)$ & & & & & & \\
\hline 3 & $2(13 \%)$ & & & & & & \\
\hline
\end{tabular}

Descriptive statistics are presented as either mean \pm standard error (SE) or absolute and relative frequencies. The regression coefficients $\beta$ may be interpreted as $\log _{2}$-fold changes where appropriate.

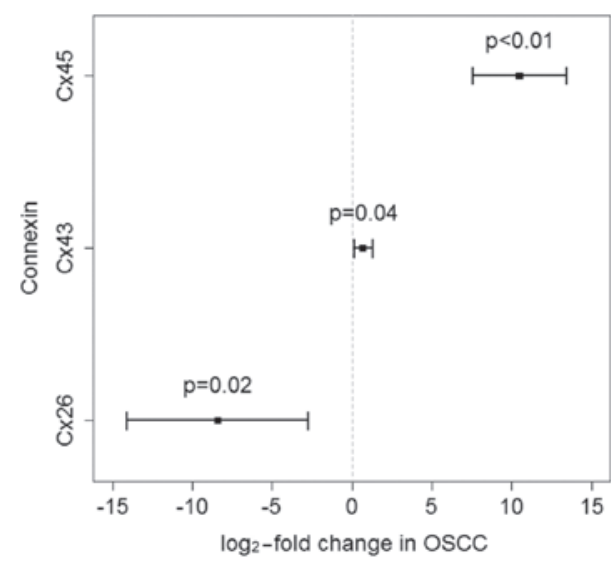

Figure $1 . \log _{2}$-fold changes in OSCC and $95 \%$ confidence intervals for the three connexins (Cxs). The displayed P-values are Bonferroni/Holm-adjusted. While Cx43 and Cx45 exhibited an upregulation in OSCC, Cx26 was downregulated. for the effect of alcohol abuse $(\mathrm{P}=0.0518)$ exhibited a trend for a possible downregulation of this $\mathrm{Cx}$ in patients abusing alcohol (Table I).

\section{Discussion}

In a previous histomorphometrical analysis (23), we investigated the protein expression patterns of the Cx subtypes 26, 43 and 45 in tissue samples of OSCC, dysplasia-free oral mucosa and LNM in 35 primary OSCC patients and observed differential expression profiles between the tissue types. Moreover, high membrane Cx43 expression in OSSC tissues was associated with poor prognosis, and exhibited a similar prognostic tendency in microscopically unchanged oral mucosa of same patients (23). The present study was performed on tissue samples of tumours at different stages. However, the 
primary goal was not to investigate the effect of tumour stage, but rather to determine whether the $\mathrm{Cx}$ subtype expression differed at the mRNA level between OSSC and oral mucosa. Since differences between the transcriptional and protein levels of $\mathrm{Cx} 43$ have been described in an experimental rat tongue carcinogenesis model (24), we further aimed to confirm the expression of Cx subtypes at the mRNA level in OSCC tissues.

Cx45 mRNA has been shown to be more strongly overexpressed in OSCC tissues compared with intraindividual mucosa controls $(\mathrm{P}<0.01)$. In contrast to LNM, which exhibited a significant increase in the $\mathrm{Cx} 45$ protein level (23), Cx45 protein expression was not found to be significantly different between OSCC tissues and dysplasia-free oral mucosa in our previous investigation (23). There is only limited evidence of the relevance of $\mathrm{Cx} 45$ for carcinogenesis in recent publications. Cx45 is variably expressed in human lung fibroblasts and lung carcinoma cells (29), and was detected in normal lung tissue and advanced-stage mouse lung carcinomas (30). Cx45 has been extensively investigated regarding its co-expression with $\mathrm{Cx} 43$ resulting in altered gap junctions. $\mathrm{Cx} 45$ was found to be upregulated in heart failure, compared with Cx43 (31). The diffusion capacity of cationic fluorescent dyes over heteromeric gap junctions comprising $\mathrm{Cx} 45$ and $\mathrm{Cx} 43$ was found to be reduced when $\mathrm{Cx} 45$ is overexpressed (15), leading to altered intercellular voltage gating mechanisms (14). The relative upregulation of Cx45 in comparison with $\mathrm{Cx} 43$ was shown to cause an increased susceptibility to cardiac arrhythmias in vivo (13).

The Cx26 mRNA level was downregulated in OSCC tissues, as opposed to oral mucosa controls $(\mathrm{P}=0.01)$. In our histomorphometrical analysis, no $\mathrm{Cx} 26$ protein expression was detected in oral mucosa (23); however, it was increased in primary OSCC and exhibited the highest levels in local LNMs. Different studies indicated that Cx26 may be involved in tumour cell invasion and metastasis. Kanczuga-Koda et al (19) described Cx26 overexpression in corresponding LNMs compared with primary mammary carcinoma. Saito-Katsuragi et al (17) demonstrated a significant Cx26 expression in tumour cells and tumour-related microvessel endothelia during metastasis of human malignant melanoma, whereas no $\mathrm{Cx} 26$ expression was found in control tissues from either healthy dermis or nevus cell nevi. In this context, it appears likely that neoplastic cells use Cx26 to form homomeric gap junctions with tumour-associated microvessel endothelia, thus improving perivascular accumulation and preparing extravasation.

In the present investigation, $\mathrm{Cx} 43$ gene expression was marginally upregulated in OSCC tissues, unlike that in oral mucosa controls $(\mathrm{P}=0.04)$. In our previous analysis $(23)$, the cytoplasmic $\mathrm{Cx} 43$ protein level was found to be increased in primary OSCC compared with matching oral mucosa. Moreover, membrane Cx43 expression was reduced in OSCC tissues compared with oral mucosa controls, suggesting a loss of gap junctions comprising Cx43, leading to a loss of GJIC. A reduction of $\mathrm{Cx} 43$ during carcinogenesis was previously demonstrated (32). However, it has not been fully elucidated whether this loss is due to increased degradation of gap junction channels, or faulty transcription and post-transcriptional modifications within the Cxs. It was recently suggested that post-transcriptional, translational and degradation regulations play a similarly important gene transcription role in the determination of protein concentrations (33). Despite reduced $\mathrm{Cx} 43$ protein levels, normal high mRNA levels were detected (24). Budunova et al (34) investigated the expression of Cxs 26, 43 and 31.1 in mouse hyperplastic skin, papilloma and SCC. In addition to the high levels of Cx26 and Cx43 mRNA in most of the SCC, the authors observed decreased protein levels of both $\mathrm{Cx}$ subtypes in tumour plasma membranes, and concluded that the expression of these two Cxs in SCC was impaired at the post-translational level (34).

The exact functions of connexins and GJIC during oral carcinogenesis remain unclear. Connexin regulation at the transcriptional level appears to be an early event during the initiation and development of OSCC, and is maintained during tumour progression. However, the mRNA-protein correlation is variable. This may be indicative of post-transcriptional, translational and degradation regulations being relevant for the determination of $\mathrm{Cx}$ protein concentration during oral carcinogenesis.

\section{References}

1. Willecke K, Eiberger J, Degen J, Eckardt D, Romualdi A, Güldenagel M, Deutsch U and Söhl G: Structural and functional diversity of connexin genes in the mouse and human genome. Biol Chem 383: 725-737, 2002.

2. Loewenstein WR and Penn RD: Intercellular communication and tissue growth. II. Tissue regeneration. J Cell Biol 33: 235-242, 1967.

3. Mesnil M, Krutovskikh V, Piccoli C, Elfgang C, Traub O, Willecke K and Yamasaki H: Negative growth control of HeLa cells by connexin genes: Connexin species specificity. Cancer Res 55: 629-639, 1995.

4. King TJ, Fukushima LH, Donlon TA, Hieber AD, Shimabukuro KA and Bertram JS: Correlation between growth control, neoplastic potential and endogenous connexin 43 expression in HeLa cell lines: Implications for tumor progression. Carcinogenesis 21: 311-315, 2000.

5. McLachlan E, Shao Q, Wang HL, Langlois S and Laird DW: Connexins act as tumor suppressors in three-dimensional mammary cell organoids by regulating differentiation and angiogenesis. Cancer Res 66: 9886-9894, 2006.

6. Avanzo JL, Mesnil M, Hernandez-Blazquez FJ, Mackowiak II, Mori CM, da Silva TC, Oloris SC, Gárate AP, Massironi SM, Yamasaki $\mathrm{H}$ and Dagli ML: Increased susceptibility to urethane-induced lung tumors in mice with decreased expression of connexin 43. Carcinogenesis 25: 1973-1982, 2004.

7. Dubina MV, Iatckii NA, Popov DE, Vasil'ev SV and Krutovskikh VA: Connexin 43, but not connexin 32, is mutated at advanced stages of human sporadic colon cancer. Oncogene 21: 4992-4996, 2002.

8. Cronier L, Crespin S, Strale PO, Defamie N and Mesnil M: Gap junctions and cancer: New functions for an old story. Antioxid Redox Signal 11: 323-338, 2009.

9. Trosko JE, Chang CC, Upham BL and Tai MH: Ignored hallmarks of carcinogenesis: Stem cells and cell-cell communication. Ann NY Acad Sci 1028: 192-201, 2004.

10. Iacobas DA, Urban-Maldonado M, Iacobas S, Scemes E and Spray DC: Array analysis of gene expression in connexin-43 null astrocytes. Physiol Genomics 15: 177-190, 2003.

11. Iacobas DA, Scemes E and Spray DC: Gene expression alterations in connexin null mice extend beyond the gap junction. Neurochem Int 45: 243-250, 2004.

12. Yano T, Hernandez-Blazquez FJ, Omori Y and Yamasaki H: Reduction of malignant phenotype of HEPG2 cell is associated with the expression of connexin 26 but not connexin 32 Carcinogenesis 22: 1593-1600, 2001.

13. Betsuyaku T, Nnebe NS, Sundset R, Patibandla S, Krueger CM and Yamada KA: Overexpression of cardiac connexin 45 increases susceptibility to ventricular tachyarrhythmias in vivo. Am J Physiol Heart Circ Physiol 290: H163-H171, 2006.

14. Bukauskas FF, Angele AB, Verselis VK and BennettMV: Coupling asymmetry of heterotypic connexin 45/connexin 43-EGFP gap junctions: Properties of fast and slow gating mechanisms. Proc Natl Acad Sci USA 99: 7113-7118, 2002. 
15. Koval M, Geist ST, Westphale EM, Kemendy AE, Civitelli R, Beyer EC and Steinberg TH: Transfected connexin 45 alters gap junction permeability in cells expressing endogenous connexin 43. J Cell Biol 130: 987-995, 1995.

16. Ogawa K, Pitchakarn P, Suzuki S, Chewonarin T, Tang M, Takahashi S, Naiki-Ito A, Sato S, Takahashi S, Asamoto M and Shirai T: Silencing of connexin 43 suppresses invasion, migration and lung metastasis of rat hepatocellular carcinoma cells. Cancer Sci 103: 860-867, 2012

17. Saito-Katsuragi M, Asada H, Niizeki H, Katoh F, Masuzawa M, Tsutsumi M, Kuniyasu H, Ito A, Nojima $\mathrm{H}$ and Miyagawa S: Role for connexin 26 in metastasis of human malignant melanoma: Communication between melanoma and endothelial cells via connexin 26. Cancer 110: 1162-1172, 2007.

18. Ito A, Koma Y, Uchino K, Okada T, Ohbayashi C, Tsubota N and Okada M: Increased expression of connexin 26 in the invasive component of lung squamous cell carcinoma: Significant correlation with poor prognosis. Cancer Lett 234: 239-248, 2006.

19. Kanczuga-Koda L, Sulkowski S, Lenczewski A, Koda M Wincewicz A, Baltaziak M and Sulkowska M: Increased expression of connexins 26 and 43 in lymph node metastases of breast cancer. J Clin Pathol 59: 429-433, 2006.

20. Lin JH, Takano T, Cotrina ML, Arcuino G, Kang J, Liu S, Gao Q, Jiang L, Li F, Lichtenberg-Frate H, et al: Connexin 43 enhances the adhesivity and mediates the invasion of malignant glioma cells. J Neurosci 22: 4302-4311, 2002.

21. Ozawa H, Matsunaga T, Kamiya K, Tokumaru Y, Fujii M Tomita $\mathrm{T}$ and Ogawa K: Decreased expression of connexin-30 and aberrant expression of connexin-26 in human head and neck cancer. Anticancer Res 27: 2189-2195, 2007.

22. Villaret DB, Wang T, Dillon D, Xu J, Sivam D, Cheever MA and Reed SG: Identification of genes overexpressed in head and neck squamous cell carcinoma using a combination of complementary DNA subtraction and microarray analysis. Laryngoscope 110: 374-381, 2000

23. Brockmeyer P, Jung K, Perske C, Schliephake H and Hemmerlein B: Membrane connexin 43 acts as an independent prognostic marker in oral squamous cell carcinoma. Int J Oncol 45: 273-281, 2014.
24. Xia J, Liu X, Tao X, Hong Y, Chen X, Dai Y, Huang Y and Cheng B: Expression of gap junctional protein connexin 43 during 4-nitroquinoline-1-oxide-induced rat tongue carcinogenesis. J Mol Histol 40: 183-188, 2009.

25. Wolff KD, Follmann M and Nast A: The diagnosis and treatment of oral cavity cancer. Dtsch Arztebl Int 109: 829-835, 2012.

26. Fialka F, Gruber RM, Hitt R, Opitz L, Brunner E, Schliephake H and Kramer FJ: CPA6, FMO2, LGI1, SIAT1 and TNC are differentially expressed in early- and late-stage oral squamous cell carcinoma - a pilot study. Oral Oncol 44: 941-948, 2008.

27. Pfaffl MW: A new mathematical model for relative quantification in real-time RT-PCR. Nucleic Acids Res 29: e45, 2001.

28. Holm S: A simple sequentially rejective multiple test procedure. Scandinavian J Stat 6: 65-70, 1979.

29. Zhang ZQ, Hu Y, Wang BJ, Lin ZX, Naus CC and Nicholson BJ: Effective asymmetry in gap junctional intercellular communication between populations of human normal lung fibroblasts and lung carcinoma cells. Carcinogenesis 25: 473-482, 2004

30. Udaka N, Miyagi Y and Ito T: Connexin expression in mouse lung tumor. Cancer Lett 246: 224-229, 2007.

31. Yamada KA, Rogers JG, Sundset R, Steinberg TH and Saffitz J: Up-regulation of connexin 45 in heart failure. J Cardiovasc Electrophysiol 14: 1205-1212, 2003.

32. Xing Y, Xiao Y, Zeng F, Zhao J, Xiao C, Xiong P and Feng W: Altered expression of connexin- 43 and impaired capacity of gap junctional intercellular communication in prostate cancer cells. J Huazhong Univ Sci Technolog Med Sci 27: 291-294, 2007.

33. Vogel $\mathrm{C}$ and Marcotte EM: Insights into the regulation of protein abundance from proteomic and transcriptomic analyses. Nat Rev Genet 13: 227-232, 2012.

34. Budunova IV, Carbajal S and Slaga TJ: The expression of gap junctional proteins during different stages of mouse skin carcinogenesis. Carcinogenesis 16: 2717-2724, 1995. 